\title{
Performance enhancement of OCDMA system based on sequential algorithm (SeQ) code
}

\author{
C. A. S. Fazlina ${ }^{1}$, C. B. M. Rashidi' ${ }^{2}$, S. N. Azemi ${ }^{3}$, S. A. Aljunid ${ }^{4}$, S. Yaakob $^{5}$ \\ ${ }^{1,3}$ Advanced Communication Engineering, School of Computer and Communication Engineering, \\ Universiti Malaysia Perlis, Perlis, Malaysia \\ ${ }^{2}$ WIPNET, Department of Computer and Communication Systems Engineering, Faculty of Engineering, \\ Universiti Putra Malaysia (UPM), Selangor, Malaysia
}

\begin{tabular}{l} 
Article Info \\
\hline Article history: \\
Received Jul 12, 2018 \\
Revised Oct 20, 2018 \\
Accepted Nov 2, 2018 \\
\hline Keywords: \\
Bit Error Rate (BER) \\
Multiple Access Interference \\
(MAI) \\
Optical Code Division Multiple \\
Access (OCDMA) \\
Phase Induced Intensity Noise \\
(PIIN) \\
SeQ code
\end{tabular}

\begin{abstract}
This paper presents a new class of Sequential Algorithm (SeQ) code for Optical Code Division Multiple Access (OCDMA) system. The SeQ code has advantages of various cross-correlation property at any given number of users, and code weights. The result shown, at error floor BER $=10-09$, the SeQ code capability to support 190 numbers of simultaneous users was higher than those achieved by FCC (W=4), DCS (W=4) and MFH (W=4). SeQ code excellently support 190 number of users due to due to the arrangement of code algorithm and flexibility cross-correlation (0 and 1) role. In addition, $\mathrm{SeQ}$ code capable to support up to $70 \mathrm{~km}$ for bit rate 155 Mbps in comparison $622 \mathrm{Mbps}, 1 \mathrm{Gbps}$, and $2 \mathrm{Gbps}$ be able to support 40km, $30 \mathrm{~km}$ and $20 \mathrm{~km}$ respectively. Hence, we can ascertain that PIIN and MAI are successfully eliminated for SAC-OCDMA coding system.
\end{abstract}

\section{Copyright $@ 2019$ Institute of Advanced Engineering and Science.} All rights reserved.

\section{Corresponding Author:}

Siti Fazlina Binti Che 'Ad,

Advanced Communication Engineering, Centre of Excellence,

School of Computer and Communication Engineering,

Universiti Malaysia Perlis (UniMAP),

01000, Kangar, Perlis, Malaysia.

Email: eng_fazz@yahoo.com

\section{INTRODUCTION}

The A communication system transfer information from one station to another station, whether to split by a few kilometer or long-haul distances. Communication is regularly supported by an electromagnetic carrier wave that frequently able to different from a few megahertz $(\mathrm{MHz})$ to more than a few hundred TeraHertz (THz) [1]. Optical communication systems contrast in source for microwave systems only in the frequency several of the courier wave used to transmit the communication information. An enhancement in the data size of optical communication via cause of up to 10000 is possibility easily cause such as extreme carrier frequencies used for lightwave systems [2].

In multiple access, there have three types of techniques where, two main multiple access skills, which are every user is assigned at a precise time slot in time division multiple access (TDMA) and a given wavelength space in wavelength division multiple access (WDMA) [3]. For optical code division multiple access (OCDMA) skill was progressively upward in new decades previously because of the huge requirement for bandwidth consumption, internet facilities with electronic selling and tele-networking [4]. The goal was the ability to accommodate a high number of users at smaller bit rate to connect all together across the fiber [5]. 
In OCDMA system, the mainly principal attention is the code proposed where unacceptable code constructed and more synchronous users able to be slightly reduced the system implementation because of the current multiple access interference (MAI) [6]. There are similarly a number noise resources arising from the physical properties of the arrangement scheme, for example phase induce intensity noise (PIIN), thermal and shot noise, respectively. PIIN occurs severely connected to MAI because of the overlapping spectra since numerous users [7].

This noise is because of the natural release of the broadband light supply. PIIN determined by the total of the delaying users and can't be enhanced by arising the transferred power or additional amplification at the receiver part while, signal amplification happens continuously accompanied via an equivalent volume of noise and can't increase the ratio of signal power to noise power [8]. MAI is the restriction from another user transferring at the same time, which will bound the operation error possibility with the real noise in the general system [9].

A few of the operative resolution for PIIN destruction are to reduce the number of restrictions among the signals of other users, whereas the value of cross-correlation must minors as workable. Thus, the OCDMA coding scheme must have an effective address code arrangement consistent cross-correlation. Inappropriate cross correlation between the address orders enlarged [10]. The cross-correlation control the MAI which is overall and main subject in the OCDMA systems. The more the cross-correlation between any two code words, will make robust force of the MAI and inaccurate resolution which will damage the system implementation of BER [11]. Hence, the correlation properties of the code address important measure in the operation of OCDMA systems. Additionally, once the situation contains the correlation properties it correspondingly observed about the code size and the code length. The code length develops a restriction to the number of synchronous users that the OCDMA systems able to support [12].

\section{ESSENTIAL OF SEQUENTIAL ALGORITHM (SeQ) CODE DESIGN}

The family of SeQ code design is concerned mathematical prefaces to design the codes for any given number of weights and users with minimum code length. Since, optical codes may be represented as vectors, the linear algebra will be used to identify this SeQ code. The auto-correlation of each code word and the cross-correlation between any $\mathrm{Ai}=(\mathrm{a} 1, \mathrm{a} 2, \mathrm{a} 3, . . \mathrm{aN})$ two separate codeword $\mathrm{Ai}=(\mathrm{a} 1, \mathrm{a} 2, \mathrm{a} 3 . . \mathrm{aN})$ and $\mathrm{Bj}=(\mathrm{b} 1, \mathrm{~b} 2, \mathrm{~b} 3 . \mathrm{bN})$, respectively.

A short notation of $\mathrm{K}$ represented number of users in binary $[0,1]$ sequences of length $\mathrm{N}$, code weight $\mathrm{W}$ is the number of " 1 " in each codeword and the supreme cross-correlation, $\lambda$ a. The auto and crosscorrelation functions of these sequences are defined by;

$$
\begin{aligned}
& \lambda_{a}(\tau)=\sum_{i=1}^{N} a_{i} a_{i+\tau}=W \text { for } \tau=0 \\
& \lambda_{b}(\tau)=\sum_{i=1}^{N} a_{i} b_{i+\tau} \leq 1 \text { for } \tau=0
\end{aligned}
$$

It is noteworthy when scheming coding sequences such that, may be cause slightest overlying between data chips. Let $A=\{a n\}$ and $B=\{b n\}$ be the orders of length $N$ such that the vector form can be written as;

$$
\left.\begin{array}{l}
\left\{a_{n}\right\}={ }^{\prime} 0^{\prime} \text { or }{ }^{\prime} 1^{\prime}, i=0, \ldots N-1 \\
\left\{b_{n}\right\}={ }^{\prime} 0^{\prime} \text { or }{ }^{\prime} 1^{\prime}, i=0, \ldots N-1
\end{array}\right\}
$$

Then, an is a $\{0,1\}$ binary sequence, the maximum value of $\lambda_{\mathrm{a}}(\tau)$ in Equation (1) is for $\tau=0$ and is equivalent to $\mathrm{W}$, the code weight of the sequence can be expressed as;

$$
\lambda_{a}(0)=W
$$

The code words labelled by Equation (2) can expressed as;

$$
\left.\begin{array}{l}
A=\left\{a_{i}\right\}=\text { for } i=0,1, \ldots N-1 \\
B=\left\{b_{i}\right\}=\text { for } i=0,1 \ldots N-1
\end{array}\right\}
$$

In terms of the vectors A and B, Equations (1) and (2) can be written as;

$$
\left.\begin{array}{c}
\lambda_{a}(0)=A A^{T}=W \\
\lambda_{a b}(0)=A B^{T}
\end{array}\right\}
$$


Where, AT and BT denote the transfer of vectors A and B, respectively. The first Aith row for the first K user of the code matrix can be written as;

$$
A_{i}=\overbrace{11 . .1}^{W} \overbrace{0 \ldots 0}^{a_{i}}
$$

Where, the first row of $\mathrm{Ai}$ is define as;

$$
W+a_{i} ; \text { for } 1,2, \ldots K
$$

Assume that, $\mathrm{r}=\left(\mathrm{W}-\lambda_{\mathrm{ab}}\right)$ and $\mathrm{x}_{\mathrm{i}}$ can be derived as;

$$
\begin{aligned}
& a_{i}=K r+\lambda_{a b}-r(i-1)-W \\
& =r(K-i)
\end{aligned}
$$

The MAI and PIIN among users can be suppressed effectively, when the set of code can be constructed with auto and cross-correlation by decoding the signals. This requires that the address codes must appropriate, where all address code word maybe easily distinguished from a possibly shifted version of every other code word.

Notice, it is desired to generate a set of minimum length of SeQ code for $K=4, W=3$ and $\lambda a \geq 0$ and 1. Codeword of SeQ for $\mathrm{W}=3, \mathrm{~K}=4$ and $\lambda_{a} \geq 0$ and 1 as shown in Table 1:

Table 1. Codeword of SeQ for $\mathrm{W}=3, \mathrm{~K}=4$ and $\lambda_{a} \geq 0$ and 1

\begin{tabular}{cc}
\hline Basic & Parity \\
\hline$(124)$ & 1101000 \\
$(235)$ & 0110100 \\
$(346)$ & 0011010 \\
$(457)$ & 0001101 \\
\hline
\end{tabular}

Notice, the relation between $\mathrm{N}$ and $\mathrm{K}$ for $\mathrm{SeQ}$ code can be express as:

$$
N=K+2 W-3
$$

\section{NOISE PERFORMANCE ANALYSIS} which is given by,

The SNR is defined as the average signal to noise power, $\mathrm{SNR}=\mathrm{I} 2 / \sigma^{2}$ is the average power of noise

$$
\sigma^{2}=\left\langle i_{\text {shot }}^{2}\right\rangle+\left\langle i_{\text {PIIN }}^{2}\right\rangle+\left\langle i_{\text {thermal }}^{2}\right\rangle
$$

Equation (11) can be stated as,

$$
\sigma^{2}=2 e B I+I^{2} B \tau_{C}+\frac{4 K_{b} T_{n} B}{R_{L}}
$$

Power Spectrum Density (PSD) will be calculated and the photodiode current I and can be written as follows;

$$
I=\mathcal{R} \int_{0}^{\infty} G(v) d v
$$

$\mathcal{R}$ represents as the responsively of the photo-detectors. Hence the photo current I can be expressed as;

$$
I=\mathfrak{R}\left[\frac{P_{s r}[W]}{N}\right]
$$

The power of Shot noise can be written as; 


$$
\left\langle i_{\text {Shot }}^{2}\right\rangle=2 e B \mathcal{R}\left[\frac{P_{s r}}{N}\right][3 W+1]
$$

The Phase Induced Intensity Noise (PIIN) noise will dictate the broadband sources. The calculation for receiver PIIN noise directly from the total PSD of each photodiode. By using an Eq. (15) the PIIN noise at the receiver output is given by;

$$
\left\langle i_{P I I N}^{2}\right\rangle=B\left(I_{1}^{2} \tau_{c 1}+I_{1}^{2} \tau_{c 2}\right)=I^{2} * \tau_{C} * \mathrm{~B}
$$

The variance of the PIIN noise at the receiver can be expressed as;

$$
\left\langle i_{P I I N}^{2}\right\rangle=\frac{B \mathcal{R}^{2} P_{S r}^{2} K W}{N^{2} \Delta_{V}}[3 W+1]
$$

Since all equation shown the properties of $\mathrm{SeQ}$ code are unique and independent of each other, Equation (17) is also independent of the active users' data, consequently. Thermal noise is given as;

$$
\left\langle i_{\text {Thermal }}^{2}\right\rangle=\frac{4 K_{b} T_{n} B}{R_{L}}
$$

From Eqs. (14), (15), and (16), the SNR for the proposed SeQ-A code can be defined as;

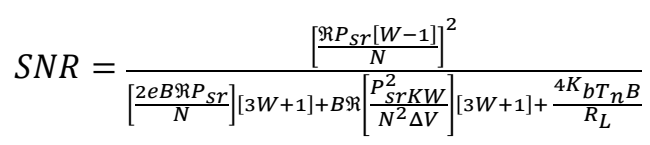

The Bit Error Rate (BER) can be obtained as;

$$
B E R=\frac{1}{2} e f r c\left(\sqrt{\frac{S N R}{8}}\right)
$$

Table 2 shows the typical parameter for theoretical algorithm for the proposed SeQ code in comparison with existing code.

Table 2. Typical parameters for theoretical calculations

\begin{tabular}{cc}
\hline Parameter & Value \\
\hline Electron's charge & $e=1.60217646 \times 10^{-19}$ coulombs \\
PD quantum & $\eta=0.75$ \\
Electrical bandwidth & $\mathrm{B}=80 \mathrm{MHz}$ \\
Boltzmann constant & $K_{b}=1.38 \times 10^{-23} \mathrm{~W} / \mathrm{K} / \mathrm{Hz}$ \\
Receiver noise & $\mathrm{T}_{\mathrm{n}}=300 \mathrm{~K}$ \\
Receiver load resistor & $\mathrm{R}_{\mathrm{L}}=1030 \Omega$ \\
Data transmission rate & $\mathrm{R}_{\mathrm{b}}=155 \mathrm{Mbps}$ \\
Broadband line width & $\Delta \lambda=3.75 \mathrm{THz}$ \\
\hline
\end{tabular}

\section{RESULTS AND ANALYSIS}

Figure 1 shows the performance of BER versus number of simultaneous users for SeQ code (W=4), FCC $(\mathrm{W}=4)$, DCS $(\mathrm{W}=4)$ and MFH $(\mathrm{W}=4)$, under a $155 \mathrm{Mbps}$ data bit rate and $\mathrm{Psr}=-10 \mathrm{dBm}$, and $\mathrm{W}=4$, respectively. The value of weight equal to four is the ideal weight for each codes. $B E R=10-9$ is the benchmark error floor for every code. At $\mathrm{BER}=10-9$, the system performance of the BER becomes increasingly degraded as the number of simultaneous users increases. SeQ code $(\mathrm{W}=4)$ capability to support 190 numbers of simultaneous users was higher than those achieved by FCC (W=4), DCS (W=4) and MFH $(\mathrm{W}=4)$. It can be seen that, FCC (W=4) was able to support 140 users, DCS $(\mathrm{W}=4)$ can accommodate 90 users, whereas MFH $(\mathrm{W}=4)$ can support only 20 simultaneous users. Since each code sequence was assigned to specific BER=10-9 error floor, the cardinality of SeQ code showed respective improvements of $35 \%$, $111 \%$ and $850 \%$ compared with those of the FCC $(\mathrm{W}=4), \mathrm{DCS}(\mathrm{W}=4)$ and MFH $(\mathrm{W}=4)$ codes. These results revealed that $\mathrm{SeQ}$ code enhances the performance of the OCDMA system than other existing codes due to the arrangement of code algorithm and flexibility cross-correlation ( 0 and 1$)$ role. 


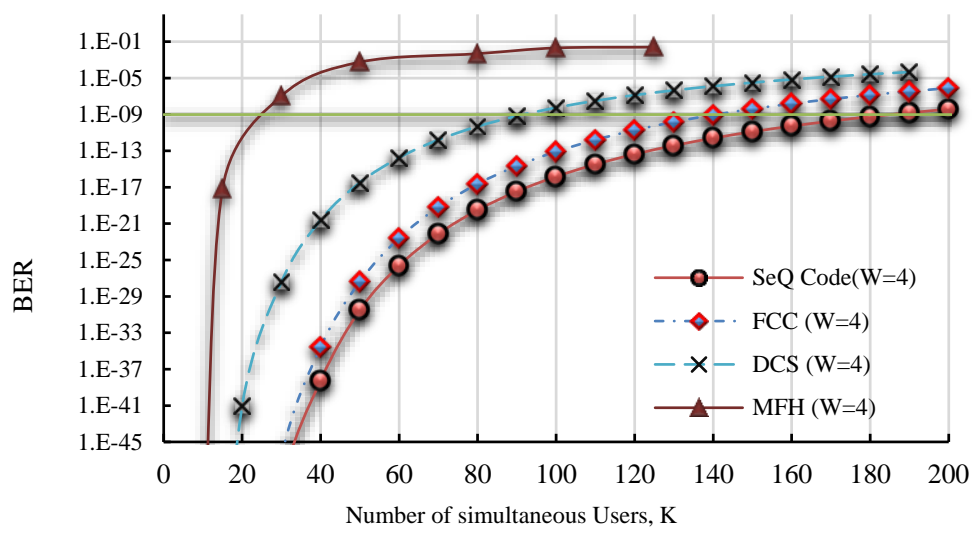

Figure 1. BER versus number of simultaneous users for SeQ code (W=4), FCC (W=4), DCS (W=4) and $\mathrm{MFH}(\mathrm{W}=4)$

Figure 2 presents the plots between performances of BER versus the fiber length of SeQ code for $155 \mathrm{Mbps}, 622 \mathrm{Mbps}, 1 \mathrm{Gbps}$ and $2 \mathrm{Gbps}$ bit rates among the three number of users. From the result obtained, at the communication error floor BER $=10-09$, the bit rate $155 \mathrm{Mbps}$ by SeQ code shows the excellent performance contrast with $622 \mathrm{Mbps}, 1 \mathrm{Gbps}$ and $2 \mathrm{Gbps}$. Whereas, at bit rate $155 \mathrm{Mbps}$ capable to reach at $70 \mathrm{~km}$ fiber length. In comparison with $622 \mathrm{Mbps}, 1 \mathrm{G}$ bps and $2 \mathrm{Gbps}$ the achievement are $40 \mathrm{~km}$, $30 \mathrm{~km}$ and $20 \mathrm{~km}$, respectively. In OCDMA, the SeQ code performs sufficiently for $70 \mathrm{~km}$ fiber length for bit rate $155 \mathrm{Mbps}$ at threshold $\mathrm{BER}=10-09$. It is obviously monitored via eye diagram showed, at $155 \mathrm{Mbps}$ the eye diagram produced a bigger eye opening between top and bottom level. The peak of eye opening at the certain time interval illustrates the noise margin or immunity to noise. Whereas, in contrast with $622 \mathrm{Mbps}, 1$ Gbps and 2 Gbps presents the more increase bit rate more eye diagram become closer the more tough to distinguish amongst the ones and zeros in the signal. From this performance, the SeQ code at bit rate 155 Mbps able effectively eliminate and suppressed the produced PIIN and MAI for the SAC-OCDMA coding system.

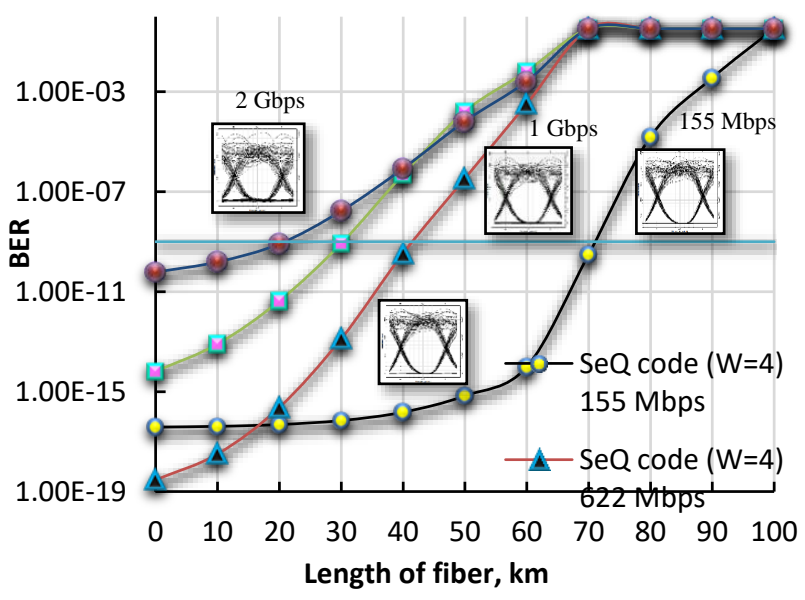

Figure 2. Performance of BER against fiber length $(\mathrm{km})$ of SeQ code $(\mathrm{W}=4)$ for different bit rates

\section{CONCLUSION}

In this paper, a new code referred as Sequential Algorithm (SeQ) code was proposed for Optical Code Division Multiple Access (OCDMA).The performance of the OCDMA system with SeQ code has been evaluated via utilizing analytical analysis and software by Optisystem. The algorithm of SeQ code develop to enhance the impact of cross - correlation that had been presented in OCDMA. At error floor BER = 10-09, SeQ code can accommodate 190 number of users the performance of BER was excellent among 200 number of users which are the largest number of users in comparison FCC (W=4), DCS (W=4) and MFH (W=4).

Performance enhancement of OCDMA system based on sequential algorithm (SeQ) code (C. A. S. Fazlina) 
SeQ code also be able to support until 70km for bit rate $155 \mathrm{Mbps}$. From the results, this SeQ code will give an opportunity in OCDMA system for better quality of service in optical access for future generation's usage.

\section{ACKNOWLEDGEMENTS}

Sponsor and financial support acknowledgments can be mentioned here. 9003-556

\section{REFERENCES}

[1] S. N. Bhusari et al., "Analysis of Self-Phase Modulation and Four-Wave Mixing in Fiber Optic Communication," International Conference on Automatic Control and Dynamic Optimization Technique, vol. 2, pp 798-803, 2016,

[2] A. O. Aldhaibani, et al, "Reducing the Effect of Noise for SAC-OCDMA System by using OFDM Modulation," Indian Journal of Science and Technology, vol. 8, pp 8-11, 2015.

[3] M. Kumari and H. Sarangal, "Performance Analysis of Zero Cross-Correlation Code in Spectral Amplitude CodingOCDMA," International Conference on Communication, Computing \& Systems, vol. 1, pp 21-24, 2014.

[4] T. H. Abd, et al., "Enhancement of Performance of a Hybrid SAC-OCDMA System using Dynamic Cyclic Shift Code," J. Phys. Opt, vol. 13, pp 12-27, 2012.

[5] T. H. Abd, et al., "New approach for evaluation of the performance of spectral amplitude coding-optical code division multiple access system on high-speed data rate," IET Commun, vol. 6, pp 1742, 2012.

[6] N. A. A. Ahmad, et al "Performance Analysis of Subcarrier OCDMA System using Recursive Combinatorial Code Based on AND Detection Technique," 3rd International Conference on Electronic Design (ICED), pp 141-145, 2016.

[7] C. B. M. Rashidi, et al., "New Approach of Flexible Cross Correlation (FCC) Algorithm for Noise Alleviation on OCDMA Systems," MUCET, pp 10-11, 2014.

[8] Z. G. Khaki et al., "Transient Correction using EDFA: In - Line Optical Fiber with Feedback," International Conference on Computing Sciences, pp 233 - 238, 2012.

[9] C.B.M. Rashidi, et al., "Cardinality Enrichment of Flexible Cross Correlation (FCC) Code for SAC-OCDMA System by Alleviation Interference Scheme (AIS)," Optik, vol. 125, pp 4889-4894, 2014.

[10] N. Nandan et al., "A Novel Interference Cancellation Technique for Optical CDMA System," IEEE International Conference on Advanced Communication Control and Computing Technologies, vol. 97, pp 730-733, 2014.

[11] M. Z. Norazimah, et al., "Impact of Different Transceiver Design on the Performance of SAC - OCDMA Systems," $2^{\text {nd }}$ International Conference on Electric Design (ICED 2014), PP 122 - 126, 2014.

[12] C. B. M. Rashidi et al., "Cardinality enhancement using Flexible Cross Correlation (FCC) code for Spectral Amplitude Coding Optical Code Division Multiple Access systems," Journal of Applied Sciences Research, vol. 12, pp. 5614-5626, 2012. 